\title{
The Effect Of Functional Endoscopic Sinus Surgery On Lung Function In Patients With Chronic Sinusitis And Nasal Polyps Without Asthma
}

\author{
${ }^{1}$ Metin Yıldırım, ${ }^{1}$ Seyda Belli, ${ }^{1}$ Cemal Ozyilmaz, ${ }^{2}$ Ozcan Ogurlu \\ ${ }^{1}$ Bagcilar Training and Research Hospital, Otorbinolaryngology, MD \\ ${ }^{1}$ Bagcilar Training and Research Hospital, Otorbinolaryngology, MD \\ ${ }^{1}$ Bagcilar Training and Research Hospital, Otorbinolaryngology, MD \\ ${ }^{2}$ Bagcilar Training and Research Hospital, Pulmonology, MD
}

\begin{abstract}
Objectives: The aim of this study was to look into how functional endoscopic sinus surgery (FESS) for CRSwNP without asthma affects lung function. The investigators aimed to determine any correlation between Lund-Kennedy scores, Lund-Mackay scores and pulmonary function.

Methods: All participants underwent nasal endoscopic examination and CT scanning paranasally. Lund-Kennedy endoscopy and Lund-Mackay CT scores were calculated and compared with postoperative findings. Statistical analysis was performed to compare preoperative and postoperative spirometry findings to assess efficacy of surgery on pulmonary function.
\end{abstract}

Results: There were no statistically significant differences between the Lund-Mackay scores for primary FESS and revision. Nevertheless, Lund-Kennedy scores did show evidence of greater statistical significance when comparing revision FESS and primary FESS $(p=0.04)$ With respect to both primary and revision FESS patients there was no statistical significance between the preoperative values of FEV1, FEV1/FVC, FVC, and FEF25-75 and the same parameters measured one month postoperatively $(p>0.05)$.

Conclusion: Our results reveal that FVC improves following FESS in cases of CRSwNP that are not also asthmatic. No relationship was demonstrable between how severe the disease is and how the lung functions. Further research that looks at FESS in asymptomatic cases of airway obstruction over more prolonged follow-up needs to be undertaken.

\section{Introduction}

Chronic rhinosinusitis (CRS) is an umbrella term for several disorders characterised by two symptoms or more lasting longer than 12 weeks. Sufferers may have pain or pressure over the face, a pus-filled discharge from the nose, blocked nose and hyposmia. The presence of a chronic inflammatory process can be demonstrated either radiologically or endoscopically ${ }^{[1]}$. CRS occurs frequently in the general population. According to the National Ambulatory Medical Care Survey, amongst Americans, between 14 and $16 \%$ of the population have experienced CRS. The cost in terms of lost productivity and additional healthcare expenditure runs into the billions of dollars ${ }^{[2-4]}$.

A recent division of CRS into two types uses the presence or absence of nasal polyps as a distinguishing feature ${ }^{[5]}$.
Correspondence: Dr. ŞEYDA BELLI, Bagcilar Training and Research Hospital, İSTANBUL, TÜRKIYE e-mail: drseydabelli@gmail.com

Received: July 16, 2018; Accepted: August 5, 2018
Online available at: www.entupdates.or DOI:10.32448/entupdates.459007 
If nasal polyps are present within the nasal cavity, they indicate that the upper airway is inflamed. The inflammation may be secondary to a variety of causes, such as persistent bacterial or mycological infection, cystic fibrosis, dysfunctional cilia ${ }^{[6]}$ or Peutz-Jegher Syndrome ${ }^{[7]}$. The polyposis itself results from chronic inflammation of eosinophilic aetiology within the mucosae of the nose and adjacent structures. It may be found in isolation, with an unknown cause, or be a feature of chronic rhinosinusitis with nasal polyposis (CRSwNP) ${ }^{[7]}$. In this article, the definition used for CRSwNP is that of the European Position Paper on Rhinosinusitis and Nasal Polyps ${ }^{[7]}$. The prevalence of nasal polyposis approaches $4 \%{ }^{[5,8,9]}$ and treatment is problematic due to the disease's severity ${ }^{[10]}$. There is a proven association with asthma, especially asthma in association with NSAID/aspirin intolerance, the so-called Samter Triad ${ }^{[11]}$. Sufferers from both asthma and COPD (chronic obstructive pulmonary disease) commonly also have CRS and rhinitis ${ }^{[12,13]}$. Williamson and colleagues ${ }^{[14]}$ discovered that cases of CRSwNP have a reduction in their airways that does not lead to symptoms, whilst Ciprandi and colleagues ${ }^{[15]}$ found $53.7 \%$ of cases with chronic hayfever had measures of reduced lung function. As yet, how operative therapy for CRS influences inflammatory processes in the lower airways remains under-researched ${ }^{[16]}$. For this reason, the current study was undertaken to look into how functional endoscopic sinus surgery (FESS) for CRSwNP without asthma affects lung function.

\section{Material And Methods}

The research has a prospective methodology. Ethical approval was obtained from the Bagcilar Teaching And Research Hospital Non-Invasive Clinical Research Ethical Committee, on 21.03.2017 with the registration number 2017/566. Participants were recruited who had CRSwNP of treatment-resistant type. Exclusion criteria were: smoker, known asthmatic or using bronchodilatory therapy or similar.

All participants underwent nasal endoscopic examination and CT scanning paranasally. Lund-Kennedy endoscopy and Lund-Mackay CT scores were calculated. Preoperative spirometry was performed to assess baseline pulmonary function.

In total, 30 cases of CRSwNP had FESS performed by otorhinolaryngologists at a single centre. Histopathological examination showed chronic inflammatory-type nasal polyps in all cases. All participants received one month's steroid treatment for one month post-operatively. The steroid was given as intranasal mometasone furoate. Follow-up examinations were carried out at one week and one month post-operatively and spirometry was also done one month after FESS.

The investigators aimed to determine any correlation between Lund-Kennedy scores, Lund-Mackay scores and pulmonary function. Likewise, the study aimed to clarify how FESS influences pulmonary function in cases of CRSwNP without asthma.

Statistical analyses were carried out by means of the NCSS (Number Cruncher Statistical System) 2007 Statistical Software (Utah, USA) application. Descriptive statistics (means and corresponding SD) were obtained and the groups compared in binary fashion using independent $t$ tests and the Pearson Correlation tests. A value of $\mathrm{p}<0.05$ was taken to indicate statistical significance.

\section{Results}

The male:female distribution amongst participants was 8:22 and the mean age was 44.37 years. The mean Lund-Kennedy endoscopy score was 7.77 and the mean Lund-Mackay CT score was 19.17. The mean Lund-Kennedy endoscopy score in the primary FESS cases was 7.38 whilst in the revision FESS patients it was 8.67. The mean Lund-Mackay CT score in primary FESS patients was 19.14 and in revision FESS patients was 19.22. Table-1 lists these values and also the preoperative and postoperative spirometry values. These last include the percentage of predicted forced expiratory volume in 1 second (\%FEV1), forced vital capacity (\%FVC), forced expiratory volume in 1 second/forced vital capacity ratio (\%FEV1/FVC) and mean forced expiratory flow between 25 and 75 per cent of the forced vital capacity (\%FEF25-75). 9 out of 30 patients had previously undergone one or more FESS. The values for revision FESS patients can be found in Table 2 .

There were statistically significant differences between the postoperative 1st month FVC and the preoperative FVC values $(\mathrm{p}=0.019)$. FEV1, FEV1/FVC and FEF25-75 values were not different at the level of statistical significance between preoperative and postoperative 1st month measurements $(\mathrm{p}=0.167, \mathrm{p}=0.568, \mathrm{p}=0.09)$. The study showed that FESS surgery for the treatment of CRSwNP increased the patient's FVC (Table 3).

As it was anticipated that disease severity would affect the patient's lung function, the correlation between disease severity and pulmonary function was analysed. There were 
Table 1: Preoperative and postoperative spirometric measurements and endoscopic scores.

\begin{tabular}{|c|c|c|c|c|}
\hline & $\mathbf{N}$ & Minimum & Maximum & Mean \pm SS \\
\hline Age & 30 & 18 & 68 & $44.37 \pm 12.21$ \\
\hline Lund-Kennedy endoscopy score & 30 & 5 & 11 & $7.77 \pm 1.59$ \\
\hline Lund-Mackay CT score & 30 & 10 & 24 & $19.17 \pm 4.11$ \\
\hline Pre-op \% FVC & 30 & 58 & 125 & $87.2 \pm 17.02$ \\
\hline Post-op 1st month \% FVC & 30 & 61 & 129 & $91.33 \pm 13.84$ \\
\hline Pre-op \% FEV1 & 30 & 37 & 130 & $85.37 \pm 20.87$ \\
\hline Post-op 1st month \% FEV1 & 30 & 42 & 129 & $88.2 \pm 15.94$ \\
\hline Pre-op \% FEV1/FVC & 30 & 63 & 114 & $96.33 \pm 10.96$ \\
\hline Post-op 1st month \% FEV1/FVC & 30 & 68 & 119 & $95.7 \pm 10.48$ \\
\hline Pre-op \% FEF 25-75 & 30 & 19 & 147 & $79.2 \pm 30.48$ \\
\hline Post-op 1st month \% FEF 25-75 & 30 & 21 & 177 & $84.53 \pm 33.15$ \\
\hline
\end{tabular}

Table 2: Preoperative and postoperative spirometric measurements, endoscopic scores, CT scores of primary and revision cases.

\begin{tabular}{|c|c|c|c|c|c|}
\hline $\mathbf{P} / \mathbf{R}$ & & $\mathbf{N}$ & Minimum & Maximum & Mean \pm SS \\
\hline \multirow{10}{*}{ Primer n:21 (\%70) } & Age & 21 & 18 & 68 & $44.86 \pm 13.51$ \\
\hline & Lund-Kennedy endoscopy score & 21 & 5 & 11 & $7.38 \pm 1.66$ \\
\hline & Lund-Mackay CT score & 21 & 10 & 24 & $19.14 \pm 4.46$ \\
\hline & Pre-op \% FVC & 21 & 58 & 125 & $90.52 \pm 17.82$ \\
\hline & Post-op 1st month \% FVC & 21 & 61 & 129 & $93.86 \pm 15.18$ \\
\hline & Pre-op \% FEV1 & 21 & 37 & 130 & $87.57 \pm 23.22$ \\
\hline & Post-op 1st month \% FEV1 & 21 & 42 & 129 & $88.81 \pm 18.28$ \\
\hline & Pre-op \% FEV1/FVC & 21 & 63 & 114 & $94.19 \pm 11.54$ \\
\hline & Post-op 1st month \% FEV1/FVC & 21 & 68 & 110 & $93.14 \pm 10.19$ \\
\hline & Pre-op \% FEF 25-75 & 21 & 19 & 147 & $77.62 \pm 32.95$ \\
\hline \multirow{12}{*}{ Revision n:9 (\%30) } & Post-op 1st month \% FEF 25-75 & 21 & 21 & 150 & $79.24 \pm 30.96$ \\
\hline & Age & 9 & 31 & 56 & $43.22 \pm 9.03$ \\
\hline & Lund-Kennedy endoscopy score & 9 & 7 & 10 & $8.67 \pm 1$ \\
\hline & Lund-Mackay CT score & 9 & 14 & 22 & $19.22 \pm 3.38$ \\
\hline & Pre-op \% FVC & 9 & 60 & 103 & $79.44 \pm 12.63$ \\
\hline & Post-op 1st month \% FVC & 9 & 72 & 96 & $85.44 \pm 7.92$ \\
\hline & Pre-op \% FEV1 & 9 & 61 & 109 & $80.22 \pm 13.72$ \\
\hline & Post-op 1st month \% FEV1 & 9 & 75 & 99 & $86.78 \pm 9.07$ \\
\hline & Pre-op \% FEV1/FVC & 9 & 86 & 112 & $101.33 \pm 7.89$ \\
\hline & Post-op 1st month \% FEV1/FVC & 9 & 90 & 119 & $101.67 \pm 9.01$ \\
\hline & Pre-op \% FEF 25-75 & 9 & 51 & 121 & $82.89 \pm 25.15$ \\
\hline & Post-op 1st month \% FEF 25-75 & 9 & 51 & 177 & $96.89 \pm 36.63$ \\
\hline
\end{tabular}


Table 3: Preoperative and postoperative lung functions.

\begin{tabular}{lccc}
\hline & Pre-op & Post-op 1st month & $\mathbf{p}$ \\
\hline \% FVC & $87.2 \pm 17.02$ & $91.33 \pm 13.84$ & 0.019 \\
\% FEV1 & $85.37 \pm 20.87$ & $88.2 \pm 15.94$ & 0.167 \\
\% FEV1/FVC & $96.33 \pm 10.96$ & $95.7 \pm 10.48$ & 0.568 \\
\% FEF 25-75 & $79.2 \pm 30.48$ & $84.53 \pm 33.15$ & 0.09 \\
\hline
\end{tabular}

Paired $t$-test

no statistically significant correlations between Lund-Kennedy scores and Lund-Mackay scores, nor with preoperative FEV1, FEV1/FVC, FVC or FEF25-75 (p>0.05) (Table 4).

Table 4: Preoperative and postoperative spirometric measurements, endoscopic scores, andCT scores.

\begin{tabular}{llcc}
\hline \hline & & $\begin{array}{c}\text { Lund-Kennedy } \\
\text { endoscopy score }\end{array}$ & $\begin{array}{l}\text { Lund-Mackay } \\
\text { CT score }\end{array}$ \\
\hline Pre-op \% FVC & $\mathrm{r}$ & -0.156 & 0.102 \\
& $\mathrm{p}$ & 0.410 & 0.592 \\
Pre-op \% FEV1 & $\mathrm{r}$ & -0.327 & -0.04 \\
& $\mathrm{p}$ & 0.078 & 0.833 \\
Pre-op \% FEV1/FVC & $\mathrm{r}$ & -0.282 & -0.03 \\
& $\mathrm{p}$ & 0.131 & 0.877 \\
Pre-Op \% FEF 25-75 & $\mathrm{r}$ & -0.269 & -0.074 \\
& $\mathrm{p}$ & 0.151 & 0.699 \\
\hline
\end{tabular}

Pearson Correlation test

Cases involving both primary and revision FESS were then compared. There were no statistically significant differences between the Lund-Mackay scores for primary FESS and revision FESS (p: 0.962). Nevertheless, Lund-Kennedy scores did show evidence of greater statistical significance when comparing revision FESS and primary FESS $(\mathrm{p}=0.04)$ (Table 5). With respect to both primary and revision FESS patients there was no statistical significance between the preoperative values of FEV1, FEV1/FVC, FVC, and FEF25-75 and the same parameters measured one month postoperatively ( $>0.05)$ (Table 6).

\section{Discussion}

Chronic rhinosinusitis is an umbrella term for several disorders characterised by two symptoms or more lasting longer than 12 weeks. Sufferers may have pain or pressure
Table 5: Endoscopic scores and CT scores of primary and revision cases.

\begin{tabular}{lccc}
\hline \hline & Primary FESS & Revision FESS & $\mathbf{p}$ \\
\hline $\begin{array}{l}\text { Lund-Kennedy } \\
\text { endoscopy score }\end{array}$ & $7.38 \pm 1.66$ & $8.67 \pm 1$ & 0.04 \\
\begin{tabular}{l} 
Lund-Mackay CT score \\
\hline
\end{tabular} & $19.14 \pm 4.46$ & $19.22 \pm 3.38$ & 0.962 \\
\hline
\end{tabular}

Independent $t$-test

over the face, a pus-filled discharge from the nose, blocked nose and hyposmia. The presence of a chronic inflammatory process can be demonstrated either radiologically or endoscopically ${ }^{[1]}$. A recent division of CRS into two types uses the presence or absence of nasal polyps as a distinguishing feature ${ }^{[5]}$.

It has already been demonstrated by other researchers investigating nasal polyposis that applying steroids locally, or using mometasone furoate as an intranasal spray, can lead to both statistically and clinically significant reductions in polyp magnitude and airway obstruction, and helps counter hyposmia ${ }^{[17,18]}$. Nonetheless, FESS remains a treatment of choice where nasal polyps have failed to respond to pharmacological measures, despite optimisation.

Sufferers from both asthma and COPD (chronic obstructive pulmonary disease) commonly also have CRS and rhinitis ${ }^{[12,13]}$. Allergic rhinitis is proven to be a risk factor in becoming asthmatic. This connection may be explicable by the 'united airway disease' hypothesis ${ }^{[5,19]}$. A recent finding is that, even where symptomatic/overt pulmonary disease is absent, sufferers from nasal polyposis had reduced pulmonary function ${ }^{[20]}$. CRS was found to be associated with reductions in pulmonary function typical of obstructive disease, whether asthma was known to be present or not ${ }^{[21]}$. Cases of rhinitis where the sputum revealed eosinophilia were associated with reduced pulmonary function, even where the airways were not hyperresponsive ${ }^{[22]}$. Despite these findings, how nasal polyps relate to lung function remains incompletely elucidated, as does how the histopathological findings in different parts of the respiratory tract tie up.

From the literature, it appears that Kariya et al ${ }^{[20]}$ were the first to report the latent obstruction in low diameter airways associated with CRS. Their suggestion was that obstructive pulmonary alterations were present in CRS cases, even where they caused no symptoms and had not led to a diagnosis of obstructive airway disease. Ciprandi $e t$ al. ${ }^{[15]}$ concluded that $53.7 \%$ of chronic allergic rhinitis cases had associated decreases in measures of lung function. 
Table 6: Lung functions of primary and revision cases.

\begin{tabular}{|c|c|c|c|c|}
\hline & & Primary FESS & Revision FESS & $p^{*}$ \\
\hline \multirow{3}{*}{$\%$ FVC } & Pre-op & $90.52 \pm 17.82$ & $79.44 \pm 12.63$ & 0.103 \\
\hline & Post-op 1st month & $93.86 \pm 15.18$ & $85.44 \pm 7.92$ & 0.129 \\
\hline & $\mathrm{p} \neq$ & 0.083 & 0.143 & \\
\hline \multirow{3}{*}{$\%$ FEV1 } & Pre-op & $87.57 \pm 23.22$ & $80.22 \pm 13.72$ & 0.386 \\
\hline & Post-op 1st month & $88.81 \pm 18.28$ & $86.78 \pm 9.07$ & 0.755 \\
\hline & $\mathrm{p} \ddagger$ & 0.625 & 0.066 & \\
\hline \multirow{3}{*}{$\%$ FEV1/FVC } & Pre-op & $94.19 \pm 11.54$ & $101.33 \pm 7.89$ & 0.103 \\
\hline & Post-op 1st month & $93.14 \pm 10.19$ & $101.67 \pm 9.01$ & 0.039 \\
\hline & $p \neq$ & 0.311 & 0.912 & \\
\hline \multirow{3}{*}{ \% FEF 2575} & Pre-op & $77.62 \pm 32.95$ & $82.89 \pm 25.15$ & 0.672 \\
\hline & Post-op 1st month & $79.24 \pm 30.96$ & $96.89 \pm 36.63$ & 0.186 \\
\hline & $\mathrm{p} \neq$ & 0.499 & 0.123 & \\
\hline
\end{tabular}

*Independent t-test $¥$ Paired t-test

Williamson et al. ${ }^{[14]}$ found the airways were impaired subclinically and FEV1 and FEF25-75 were both diminished, in CRSwNP. Tanaka et al. revealed that an FEV1/FVC below $75 \%$ was present in $20 \%$ of cases of CRSwNP, but in such cases, asthma had not been diagnosed. Lee and colleagues ${ }^{[24]}$ reached similar conclusions. Their finding was that if features of chronic sinusitis and nasal polyps were visible on CT, the airway would present obstacles to flow at a subclinical level, even if no underlying pulmonary pathology was present. Zhang et al ${ }^{[2]}$ investigated cases where FEF25-75 and FEV1 were diminished, and found that reduced pulmonary function had a correlation with chronic sinusitis and nasal polyps as shown by CT, in the absence of disease affecting the lower respiratory tract. They were able to show, too, that FEV1 and FEF25-75 were lowest in cases of CRSwNP, compared to CRS without nasal polyposis and cases lacking CRS altogether.

The authors' belief is that CRSwNP is indeed associated with more frequent reductions in measures of lung function, and for this reason, they aimed to investigate how the severity of disease relates to changes in lung function. The study findings do not, however, support a definite correlation between the scores for Lund-Mackay (CT), Lund-Kennedy (endoscopy) and the measures for lung function recorded preoperatively. The severity of the in- flammatory process or the magnitude of polyps alone do not predict pulmonary functional values.

Recently, the following suggestions have been made as to how disease in different portions of the airway is related: (a) inflammatory substances released in the nose or liberated antigens cause stimulation lower down in the respiratory tract (b) that there are reflexes connecting the nose and bronchi and pharynx and bronchi (c) histologically, the upper and lower airways share many similarities and the mucosae respond similarly (d) localised disease is amplified systemically ${ }^{[25,26]}$. Vizzaccaro et al. ${ }^{[27]}$ reported on the existence of a nasobronchial reflex connecting the upper and lower portions of the airway. Stimulation of the nasal mucosal surface or the paranasal sinuses led to a reflex contraction of involuntary muscle within the bronchi, which could account for the increased resistance to airflow and the diminution in pulmonary function. Likewise, if the area of the pharynx draining the nose and sinuses is stimulated posteriorly, the bronchi were observed to contract, with resultant fall in flow of air through the airway. Airway hyperreactivity was observed in both CRS with and without accompanying asthma when there was a flare-up ${ }^{[28]}$.

It is debateable how far FESS for CRSwNP can ameliorate asthma. Uri et al., reporting on a case series with nasal polyposis and accompanying asthma $(n=13)$, stated that FESS offered no benefit to asthmatics whose nasal polyps 
were very severe. Ragab et al. ${ }^{[29]}$, examining a subgroup of their study who had both nasal polyposis and asthma, remarked that asthma improved both subjectively and objectively, although this was not borne out statistically. Ikeda and colleagues do, however, clearly state that FESS can enhance lung function in those cases where asthma and chronic sinusitis co-exist ${ }^{[13]}$. In a similar fashion, Vleming's series of 30 cases with both nasal polyps and asthma had improvement in their measures of lung function $64 \%$ of the time ${ }^{[30]}$.

Whilst research into the benefit of FESS for asthma does exist, similar research involving subclinical airway flow reduction does not. For this reason, we used FESS on cases with CRSwNP, but without clinically diagnosed asthma. One finding was the statistically significant increase in FVC at 1 month post FESS, indicative of a connection between upper and lower portions of the airway. But alongside this, FESS seems not to have altered FEV1, FEV1/ FVC or FEF-25-75. However, the spirometry was not repeated at either 6 months or 1 year post-operatively and the possibility exists that these values might have altered at those points. Lamblin and colleagues ${ }^{[31]}$ noted that cases

\section{References}

1) Rosenfeld RM, Andes D, Bhattacharyya N, Cheung D, Eisenberg $S$, Ganiats TG, et al. Clinical practice guideline: adult sinusitis. Otolaryngol Head Neck Surg 2007;137(3 Suppl):S1-31

2) Zhang L, Zhang L, Zhang CH, Fang XB, Huang ZX, Shi QY, et al. The Lung Function Impairment in Non-Atopic Patients With Chronic Rhinosinusitis and Its Correlation Analysis. Clin Exp Otorhinolaryngol. 2016 Dec; 9(4): 339-345

3) Cherry DK, Woodwell DA. National Ambulatory Medical Care Survey: 2000 summary. Adv Data 2002;(328):1-32

4) Anon JB, Jacobs MR, Poole MD, Ambrose PG, Benninger MS, Hadley JA, et al. Antimicrobial treatment guidelines for acute bacterial rhinosinusitis. Otolaryngol Head Neck Surg 2004;130(1 Suppl):1-45

5) Fokkens W, Lund V, Mullol J. EP3OS 2007: European position paper on rhinosinusitis and nasal polyps 2007. A summary for otorhinolaryngologists. Rhinology 2007;45:97-101

6) Mygind N, Lund V. Intranasal corticosteroids for nasal polyposis : biological rationale, efficacy, and safety. Treat Respir Med 2006;5: 93-102

7) de Leng WW, Jansen M, Keller J, de Gijsel M, Milne A, Morsink F et al. Peutz-Jeghers syndrome polyps are polyclonal with expanded progenitor cell compartment. Gut 2007;56:1475-1476

8) Hedman J, Kaprio J, Poussa T, Nieminen MM. Prevalence of asthma, aspirin intolerance, nasal polyposis and chronic obstructive of nasal polyposis that was treatment-resistant to steroid therapy and had undergone nasal surgery, had an ongoing reduction in FEV1 and features showing obstructed airways 4 years after intranasal ethmoidectomy. Our own study resembles Lamblin's ${ }^{[31]}$, and it showed FESS to be effective. It would be pertinent, therefore, if our study extended the follow-up period to 1 year, specifically looking at whether FEV1 declines.

\section{Conclusion}

Our results reveal that FVC improves following FESS in cases of CRSwNP that are not also asthmatic. No relationship was demonstrable between how severe the disease is and how the lung functions. The limitations of the study meant there needs to be caution in interpreting the results. It is quite possible that spirometric measures of lung function (FEV1, FEV1 / FVC, FEF25-75), if they had been measured at 6 months and 1 year post-FESS, would have shown a decline. Further research that looks at FESS in asymptomatic cases of airway obstruction over more prolonged follow-up needs to be undertaken.

pulmonary disease in a populationbased study. Int $\mathrm{J}$ Epidemiol 1999;28:717-722

9) Johansson L, Akerlund A, Holmberg K, Melen I, Bende M. Prevalence of nasal polyps in adults: the Skovde population-based study. Ann Otol Rhinol Laryngol 2003;112: 625-629

10) Klossek JM, Neukirch F, Pribil C, Jankowski R, Serrano E, Chanal I et al. Prevalence of nasal polyposis in France: a cross-sectional, case-control study. Allergy 2005;60: 233-237

11) Benninger MS, Ferguson BJ, Hadley JA, Hamilos DL, Jacobs M, Kennedy DW et al. Adult chronic rhinosinusitis: definitions, diagnosis, epidemiology, and pathophysiology. Otolaryngol Head Neck Surg 2003; 129(3 Suppl.): S1-S32

12) Uri N, Cohen-Kerem R, Barzilai G, Greenberg E, Doweck I, Weiler-Ravell D. Functional endoscopic sinus surgery in the treatment of massive polyposis in asthmatic patients. J Laryngol Otol 2002;116:185-189

13) Ikeda K, Tanno N, Tamura G, Suzuki H, Oshima T, Shimomura A et al. Endoscopic sinus surgery improves pulmanary function in patients with asthma associated with chronic sinusitis. Ann Otol Rhinol Laryngol 1999 Apr;108(4):355-9

14) Williamson PA, Vaidyanathan $S$, Clearie $K$, Barnes M, Lipworth BJ. Airway dysfunction in nasal polyposis: a spectrum of asthmatic disease? Clin Exp Allergy 2011;41(10):1379-85 
15) Ciprandi G, Cirillo I, Vizzaccaro A, Monardo M, Tosca MA. Early bronchial airflow impairment in patients with persistent allergic rhinitis and bronchial hyperreactivity. Respir Med 2005;99(12):160612

16) Ehnhage A, Olsson P, Kölbeck KG, Skedinger M, Dahlén B, Alenius $\mathrm{M}$ et al. Functional endoscopic sinus surgery improved asthma symptoms as well as PEFR and olfaction in patients with nasal polyposis Allergy 2009; 64: 762-769

17) Holmström M. Clinical performance of fluticasone propionate nasal drops. Allergy 1999;54(Suppl. 53):21-25

18) Stjarne P, Blomgren K, Caye'-Thomasen $P$, Salo S, Söderström T. The efficacy and safety of once-daily mometasone furoate nasal spray in nasal polyposis: a randomized, double-blind, placebo-controlled study. Acta Otolaryngol 2006;126:606-612

19) Brozek JL, Bousquet J, Baena-Cagnani CE, Bonini S, Canonica GW, Casale TB et al. Allergic Rhinitis and its Impact on Asthma (ARIA) guidelines: 2010 revision. J Allergy Clin Immunol 2010;126:466-76

20) Kariya S, Okano M, Oto T, Higaki T, Makihara S, Haruna $T$ et al. Pulmonary function in patients with chronic rhinosinusitis and allergic rhinitis. J Laryngol Otol 2014;128:255-62

21) Kariya S, Okano M, Higaki T, Noyama Y, Haruna T, Ishihara H et al. Chronic rhinosinusitis patients have decreased lung function. Int Forum Allergy Rhinol 2014;4:828-33

22) Yang MS, Lee HS, Kim MH, Song WJ, Kim TW, Kwon JW et al. Rhinitis patients with sputum eosinophilia show decreased lung function in the absence of airway hyperresponsiveness. Allergy Asthma Immunol Res 2013;5:232-8
23) Tanaka S, Hirota T, Kamijo A, Ishii H, Hatsushika K, Fujieda S et al. Lung Functions of Japanese Patientswith Chronic Rhinosinusitis Who Underwent Endoscopic Sinus Surgery. Allergology International 2014;63:27-35

24) Lee SY, Yoon SH, Song WJ, Lee SH, Kang HR, Kim SS, et al. Influence of chronic sinusitis and nasal polyp on the lower airway of subjects without lower airway diseases. Allergy Asthma Immunol Res 2014;6(4):310-5

25) Bachert C, Vignola AM, Gevaert P, Leynaert B, Van Cauwenberge P, Bousquet J. Allergic rhinitis, rhinosinusitis, and asthma: one airway disease. Immunol Allergy Clin North Am 2004;24(1):19-43

26) Jani AL, Hamilos DL. Current thinking on the relationship between rhinosinusitis and asthma. J Asthma 2005;42(1):1-7

27) Vizzaccaro A, Cirillo I, Pallestrini E, Ciprandi G. Allergic rhinitis frequently impairs bronchial function. Recenti Prog Med 2004;95(5):251-3

28) McCusker CT. Use of mouse models of allergic rhinitis to study the upper and lower airway link. Curr Opin Allergy Clin Immunol 2004;4(1):11-6

29) Ragab SM, Lund VJ, Scadding G. Evaluation of the medical and surgical treatment of chronic rhinosinusitis: a prospective, randomised, controlled trial. Laryngoscope 2004;114: 923-930

30) Vleming M, Middelweerd MJ, de Vries N. Results of endoscopic sinus surgery for nasal polyps . Am J Rhinol 1991;5:173-176

31) Lamblin C, Brichet A, Perez T, Darras J, Tonnel AB, Wallaert B. Long-term Follow-up of Pulmonary Function in Patients with Nasal Polyposis. Am J Respir Crit Care Med 2000;161:406-413

This is an open access article distributed under the terms of the Creative Commons Attribution-NonCommercial-NoDerivs 3.0 Unported (CC BYNC-ND3.0) Licence (http://creativecommons.org/licenses/by-nc-nd/3.0/) which permits unrestricted noncommercial use, distribution, and reproduction in any medium, provided the original work is properly cited.

Please cite this article as: Y1ldırım M, Belli S, Ozyilmaz C, Ogurlu O. The Effect Of Functional Endoscopic Sinus Surgery On Lung Function In Patients With Chronic Sinusitis And Nasal Polyps Without Asthma. ENT Updates 2018;8(2): 93-99. 